\title{
Outcomes from Applying Design-Led Innovation in an Australian Manufacturing Firm
}

\author{
Peter Townson, Judy Matthews, and Cara Wrigley
}

\author{
"Everyone designs who changes existing ") \\ situations in preferred futures. \\ Herbert A. Simon (1916-2001) \\ In The Sciences of the Artificial
}

\begin{abstract}
Design-led innovation has recently emerged as an approach that assists companies to develop new capabilities to respond to changing markets. Previous research has shown that the application of design-led innovation to manufacturing businesses contributed to innovation across their business model, often repositioning the business and its offerings in the market. This article presents findings from a study where the researcher was embedded in an Australian firm, working four days per week for 11 months and using action research to apply design-led innovation. Deep insights from stakeholders were translated with the company staff into new value propositions for the company. This research demonstrates the largely untapped potential of an experienced designer as an innovation catalyst to help firms develop customer-inspired innovation as they use design-led innovation to overcome barriers and recognize opportunities within a changing market context. This study contributes new knowledge regarding benefits of design-led innovation in dynamic environments.
\end{abstract}

\section{Introduction}

Companies with prior success with technological innovation are often not aware of new methods of gaining information about the demands for their products and services using customer-focused methods. Design mindsets, philosophies, and principles have been implemented through design thinking (Brown, 2008, 2009), design-driven innovation (Verganti, 2009), and more recently design-led innovation (Bucolo et al., 2012). These approaches represent a powerful way to generate, shape, and deliver new value propositions and innovation in a range of companies.

Much of the literature regarding applications of design thinking, design driven innovation, and design-led innovation has focused on large firms (Brown \& Martin, 2015; Kolko, 2015; Smith, 2015; Yoo \& Kim, 2015) with an absence of research regarding small and mediumsized enterprises. In addition, although the benefits of design management programs - where design consultants have used processes and methods to assist firms to capture deep customer insights, restructure the business, and increase the firm's competitiveness - have previously been seen (Hollinger, 2012), there is scant re- search that investigates the use of designers undertaking action research projects as innovation catalysts embedded in small and medium-sized enterprises in the manufacturing sector.

The study described in this article explored possibilities of design-led innovation in small and medium-sized enterprises where a designer using action research acted as an innovation catalyst. The aim was to increase knowledge of the influence and benefits of design-led innovation in assisting companies to generate new ways of working and new possibilities for the company. The research question driving the study was: how can a small or medium-sized manufacturer use design-led innovation to overcome barriers and recognize opportunities within a changing market context? The primary goal was to identify key imperatives to assist the company overcome barriers in implementing design-led innovation into their company culture.

This research builds new knowledge in understanding the practical application of various methods within the design-led innovation framework, and their impact and effect on the company. Action research expressly encourages a collaborative approach with a company that 


\section{Applying Design-Led Innovation in an Australian Manufacturing Firm}

Peter Townson, Judy Matthews, and Cara Wrigley

is experiencing change, and is particularly important to the research aim of using design-led innovation as a mechanism to bring about organizational change. We begin by considering extant research regarding links between design and innovation before outlining methodology, describing findings, and concluding with practical implications.

\section{Design and Innovation}

Design-led innovation is a process that shifts the role of a designer to work across an organization to radically change a company's view of the value proposition offered to customers (Kyffin \& Gardien, 2009), to codesign (Chesbrough \& Schwartz, 2007), and to generate a unique and sustainable competitive advantage $(\mathrm{Bu}-$ colo \& Matthews, 2011b). With the relative newness of design-led innovation, case study research into the complexities faced by companies with the implementation and integration of this process is quite sparse. To add a new perspective, this research presents a case study of one Australian manufacturing company operating in the mining equipment, technology, and services (METS) sector, and how design-led innovation fits within their family-owned and engineering-driven organizational and cultural framework.
Design-led innovation is broadly defined as a method that allows a company to consider and evaluate radically new propositions from multiple perspectives, typically spanning user needs, business requirements, and technology demands (Bucolo et al., 2012). Key to this process is that design is core to a company's vision, strategy, culture, leadership, and development processes. The design-led innovation framework outlined below (Figure 1), provides a conceptual structure to assist the development of innovation through collaboration across the entire organization; it integrates the operational functions with the strategic vision by combining internal and external sources.

The importance and potential of thinking and working as a designer, popularly referred to as "design thinking", is increasingly being recognized as a valuable process for generating new ways of working and new solutions. Design thinking "uses the designer's sensibility and methods to match people's needs with what is technically feasible and what business strategy can convert into customer value and market opportunities" (Brown, 2008). With this widely accepted notion (Holloway, 2009; Liedtka \& Ogilvie 2010; Norman \& Verganti, 2012; Verganti, 2010; Ward et al., 2009), design thinking holds a customer-centric view by utilizing human-

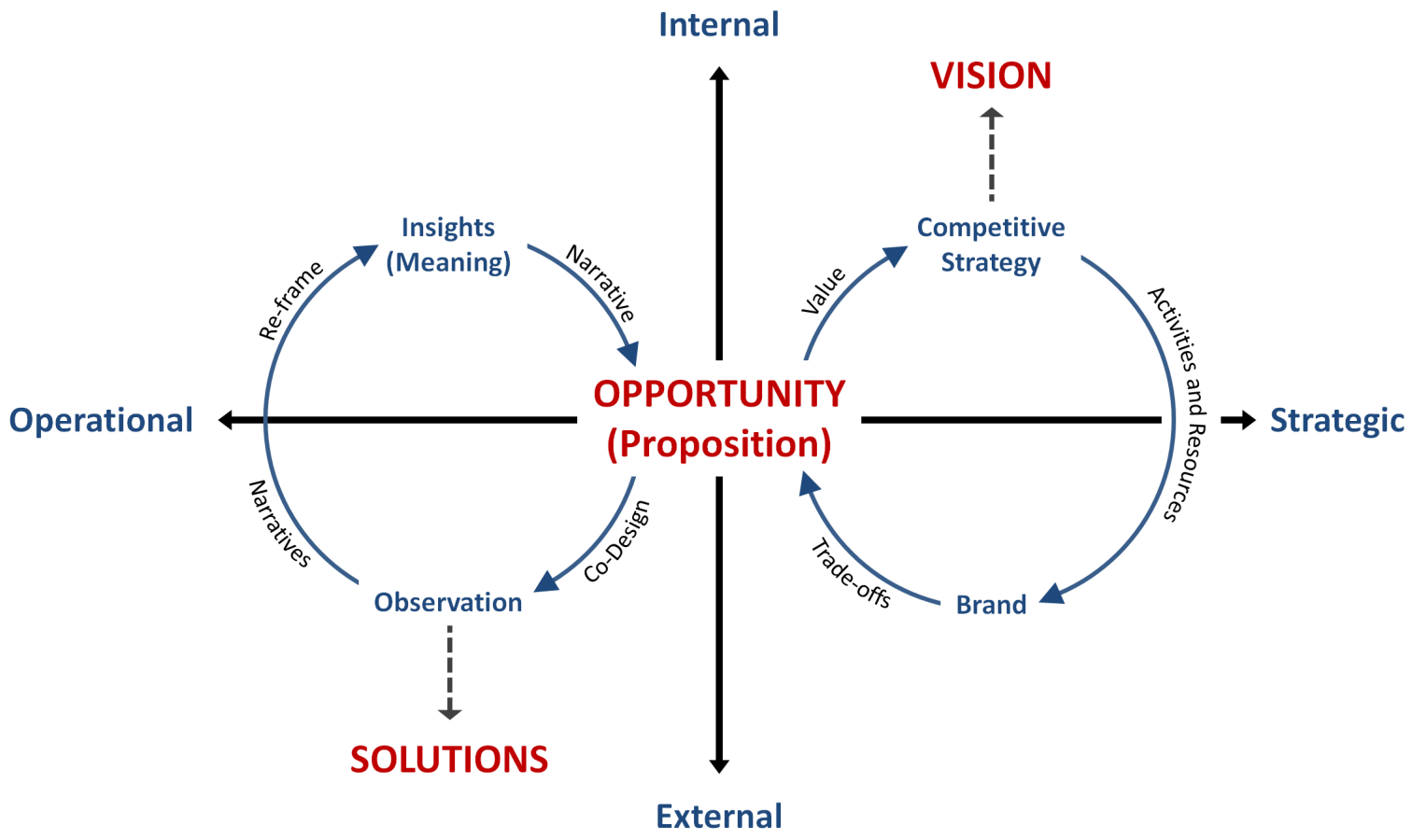

Figure 1. The design-led innovation framework (Adapted from Bucolo et al., 2012) 


\section{Applying Design-Led Innovation in an Australian Manufacturing Firm}

Peter Townson, Judy Matthews, and Cara Wrigley

centred design, experimentation, and concept prototyping as ways for a design to have an impact across the innovation process (Holloway, 2009; Norman \& Verganti, 2012; Ogilvie, 2010; Verganti, 2010; Ward et al., 2009). Design thinking as a style of thought is built upon "abductive reasoning" (C. S. Peirce cited in Cross, 1982; Martin, 2004, 2009, 2010). Abductive reasoning is "reasoning in which explanatory hypotheses are formed and evaluated" (Thagard \& Shelley, 1997); it is "characteristically 'constructive' thinking... something peculiar to design" (Cross, 1982).

Design thinking uses a method of prototyping to reduce the risk in a business model concept by testing it with the marketplace; it allows for the creative development of an idea. By taking a holistic systems perspective, design thinking creates strong value propositions that interweave through business model development so the value received is greater than the sum of the parts. Design as an innovation mechanism is an iterative process that can assist in both uncovering problems with stakeholders, analyzing some possibilities, and then synthesizing multiple elements to form new solutions. During this process, the practitioner moves between the concrete and abstract worlds of understanding (Beckman \& Barry, 2009) to build new value propositions.

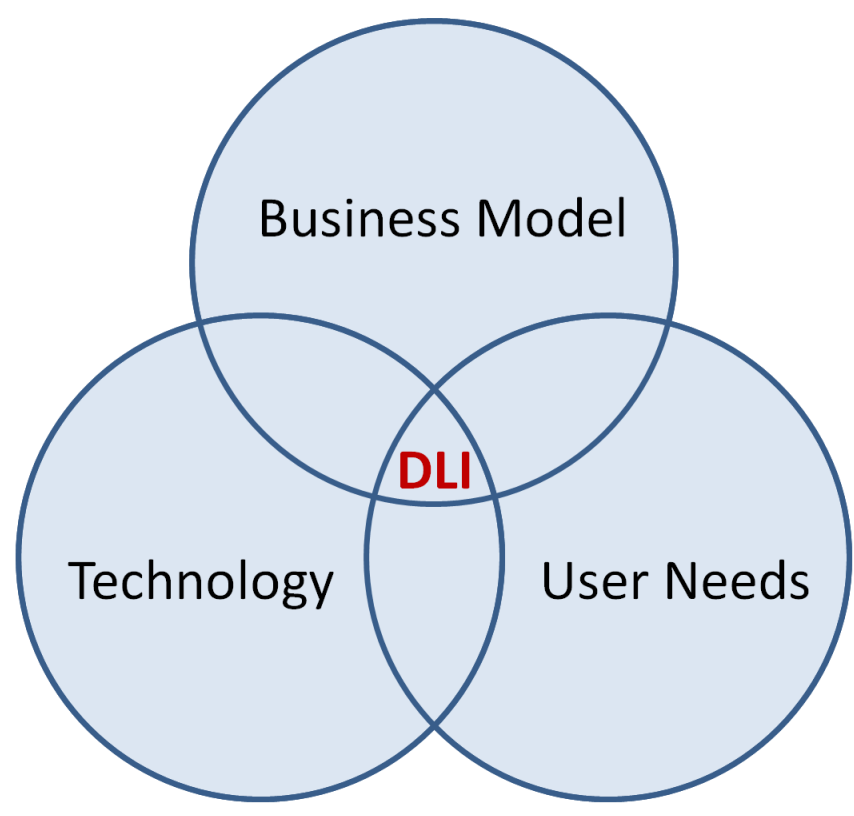

Figure 2. Design-led innovation (DLI) as derived in the intersection of fundamental business elements
Design-led innovation builds on this theory by internally aligning the solution with the company's strategy, resources, and brand. Design and innovation as organizational processes work with the staff who deliver the resultant innovation, not in isolation from organizational systems. Design-led innovation can also align corporate ideologies to fit and potentially leverage the company's internal capabilities, resources, and brand (business model) in order to generate an innovative solution that creates a competitive advantage.

Design thinking is a foundational activity within designled innovation, by leveraging a creative systems perspective that integrates the design of the business models. Design-led innovation is a philosophy that "examines every core facet of the business, to realign business strategy with customer needs and possible market futures" (Pozzey et al., 2012). Design-led innovation is derived through a creative interrelationship between these fundamental business elements to generate true value for the customer and to capture profits for growth, as shown in Figure 2.

In Australia, the mining equipment, technology and services (METS) sector is comprised of predominately engineering-based organizations (Tedesco \& Curtotti, 2005) that "provide technology and services to make the nation's mining industry competitive" (CSIRO, 2003). Exporting over AUD \$6 Billion annually (Austmine, 2012), the METS sector has become more profitable than the mining industry within Australia (CSIRO, 2003). With the relative newness of design-led innovation, case study research into the complexities faced by companies with the implementation and integration of this process is quite sparse. This research presents a case study of one Australian manufacturing company operating in the METS sector, and explores design-led innovation within their family-owned and engineeringdriven organizational and cultural framework. To maintain anonymity, here we refer to the company as METSCo.

The current Managing Director of METSCo founded the company 24 years ago by manufacturing a disruptive innovation for the mining industry. This mediumsized company of 170 staff with headquarters in Australia and international sales offices develops products and technology services in a business-to-business context. At the time of the study, the CEO and the Top Management Team were seeking the next disruptive idea to take the business to new horizons. The company had sought assistance through a funded government pro- 


\section{Applying Design-Led Innovation in an Australian Manufacturing Firm}

Peter Townson, Judy Matthews, and Cara Wrigley

gram where a graduate research student could work with the company in a 12-month research program to innovate for growth in a dynamic environment and to generate new insights about the firm and strategic and operational directions.

\section{Methodology}

Action research was selected as the method of choice to engage staff within the case organization, and it has been previously used to explore the potential of design (Swann, 2002). Action research is a cyclical process of planning, acting, observing, reflecting, and critically analyzing (Kemmis, 2009), where these cycles inform larger action research cycles (Davis, 2004). The methodology is well-suited to the journey of design-led innovation because both approaches require continuous and balanced engagement with the company in all stages of the cycle (Burns \& Brown, 2002). The process assists staff to improve their capacities to solve problems, to develop skills (including professional skills), to increase their chances of self-determination, and to have more influence on the functioning and decision-making processes of the organization.

Adopting an action research methodology, the researcher was embedded within the company, working four days a week over an 11-month period. This longitudinal research specifically investigated the barriers to design-led innovation and opportunities that developed throughout this research. The goal was to understand how the organization and culture of the METS company evolved and how it progressed towards design-led change.

Data were collected using semi-structured qualitative interviews at two distinct points of time during the research project, initially with 15 employees after three months working with the company and with 20 employees after nine months. A focus group and a reflective journal provided further relevant information. Data captured from these methods were analyzed thematically for patterns that informed the barriers, opportunities, and imperatives that resulted from a design-led innovation engagement.

The researcher worked through an iterative process of diagnosing the problem, planning the course of action, taking action with the participants, and evaluating the consequences of the action and specifying learnings, which in turn fed into the next evolution of the action research cycle in this longitudinal study. The researcher worked with the company staff in small groups to demonstrate an approach that could be piloted and then dispersed productively among all employees of the firm. Activities and interventions by the catalyst included capturing deep customer and stakeholder insights, applying these insights in operational and strategic dimensions of the business, and disseminating insights within company. Thematic analysis (Miles \& Huberman 1994) was conducted on the combined data sets in order to identify the nature of responses and change processes in the firm and to compare changes over time.

\section{Findings}

Prior to the research project at METSCo, the Managing Director had already received sponsored research into design-led innovation as a result of a desire "to find mechanisms to embed more of that (design-led innovation) thinking more deeply into the whole engineering team so that the place wasn't just dependent on (a few key people)."

The Managing Director presented his own personal journey in understanding the theory of design-led innovation, describing to the wider company his own continual journey of uncomfortable change, moments of clarity, followed by self-doubt. Participants saw the buy-in from the top as crucial: "The most successful change in this organization is directly sponsored by the Managing Director. So if he decrees something, then we all get into line and make things happen; if we don't, there is no other mechanism to make that happen." Additionally, "The tone of the Managing Director sets the tone of the management team, who sets the tone of the business."

The vision and foresight of the Managing Director to implement the design-led innovation project enabled not only the senior executives but also all employees to take a customer-centric view of their job and their company. One employee notes that, "It was his (the Managing Director's) realization about the first-class product being beaten by a second-class business model - that realization alone, is worth everything." As the company leader, the Managing Director is the culture leader and, by disseminating his own insights, like the one quoted above, encouraged and empowered the engineering-focused culture to look at innovation beyond technology.

As a result of the design-led innovation project, new opportunities were available for METSCo to exploit, to enhance their strategic development with a newfound perspective of innovation. "A business model is an op- 


\section{Applying Design-Led Innovation in an Australian Manufacturing Firm}

Peter Townson, Judy Matthews, and Cara Wrigley

portunity; a product is only a fraction of what we now know we can get, and it is almost an embarrassment." The perspective of the Managing Director "has matured from the design-led innovation process... for sure it's been part of the catalyst of maturing a vision, which has certainly changed my attitude toward (moving into new areas of innovation)."

In gauging the impact that the design-led innovation project had on his management team, the Managing Director reflects that design-led innovation, "Must be there to a greater or lesser degree in all the decision makers in (our company). They must have absorbed something, because we couldn't be going down the directions with the authority that we're going down these directions."

Within this case study, the managers of METSCo began engaging with design tools and design thinking as a way to quickly prototype businesses models in a rapidly declining economic environment. Specifically, it was the hands-on practical experience of the managers with design-led innovation that helped employees overcome barriers in design language and speculation on its theoretical application.

For METSCo to be able to deliver innovative solutions to create customer value, it was crucial to gain agreement and commitment to an organizational and cultural perspective, which allows and supports a strategic shift such as this. As one participant notes, "The first step is knowing the customers, but then if you've got to change internally, how do you do that?" This organizational change perspective is commonly raised in academic literature with regards to business model innovation (Chhatpar, 2007; Zott \& Amit, 2010), strategy (Pascale \& Sternin, 2005; Porter, 1996), and design-led innovation implementation (Matthews et al., 2012; Pozzey et al., 2012), highlighting its necessity to achieve and sustain breakthrough innovations.

Although the pressure of the declining mining cycle was forcing METSCo to change and look at its business differently, it was the awakening of senior executives to customer pressures that enabled the value of design-led innovation to be understood and experienced: "We realized that it's okay to prototype. And we started to prototype things to customers finally... that wasn't so bad. That didn't hurt us by putting something to market that wasn't totally 100\%."

From an organizational change perspective, the imperative of having active engagement of employees at all levels with design-led innovation tools and theories, and allowing their experiences become the driver for continuous change in becoming design-led, is clearly demonstrated. From a company that was justifiably focused internally on technology innovation, METSCo now is beginning to see how design-led innovation has taken a change perspective to guide a engineering culture toward the customers "job to be done", allowing the employees to gain new understanding from firsthand experiences to drive change internally.

By developing and managing design thinking capabilities with customer-facing staff, the design-led innovation catalyst was able to gain significant customer insights second-hand, while encouraging and empowering these employees to begin to analyze the market in new ways. Within design-led innovation, the role of the catalyst is one that utilizes design thinking to "translate and facilitate design observation, insight, meaning, and strategy into all facets of the company" (Wrigley \& Bucolo, 2012).

Due to the complex and remote nature of the mining industry, the researcher as catalyst (central within the framework) and a design champion in the company relied on the assumptions created and tested by the customer-facing employees and the primary source of customer insights, from where new business concepts are generated. Schön's (1983) seminal work describes a theory of knowledge as a thought process through human perception, or a "reflective conversation with the situation", where problems are framed in order to take action to gain clarity around a situation (Bucolo \& Matthews, 2011a). "Competent practitioners usually know more than they can say" (Schön, 1983). Observationally, this work was seen as valuable to rigorously understand METSCo assumptions around customer needs, as highlighted in the literature as a key feature in business model innovation (Casadesus-Masanell \& Ricart, 2010; Chhatpar, 2007; McGrath, 2010; Teece, 2010). However, the ability to test, validate, or disprove these assumptions was limited by the personal capabilities of customer-facing employees not trained in divergent learning, let alone design thinking.

The focus group captured the employee realization of the potential that channelling customer information and insights into their company could have on their job, their interaction with their colleagues, and ultimately their customers. Enabling customer-facing employees to communicate their reflective knowledge provided direct input on customer situations to progress and effectively build multi-perspective observations. 


\section{Applying Design-Led Innovation in an Australian Manufacturing Firm}

Peter Townson, Judy Matthews, and Cara Wrigley

Prototyping as a mechanism for customer-facing employees to bring customer insights back to the catalyst was crucial for the project to continue moving forward. The purpose of the prototype was to engage customerfacing employees of METSCo to work through design methods while at mine sites and to generate customer insights and reflect on them with the catalyst.

The interaction and communication with mining customers was a significant factor in changing perspectives. METSCo had traditionally placed a priority in establishing and maturing organizational processes to support their primary business in meeting market demand. Engaging customer-facing employees to prototype holistic forms of knowledge management highlights two aspects within the data: i) METSCo showed commitment in capturing and translating customer insights and ii) METSCo developed its understanding of the importance that customer-facing employees play within such a dispersed and isolated industry. By developing employee and management capabilities in "design thinking", METSCo began to holistically address its customer insight processes with an employee knowledge base that was empowered and capable to deliver new knowledge to the company.

\section{Discussion and Contributions}

Our findings show that a small or medium-sized enterprise that embraced a design-led innovation responded to the catalyst using design-led innovation processes and practices to explore and learn about their customers and to capture these insights and reconfigure their capabilities to deliver new more strategic directions and increased competitiveness. These findings contribute to a deeper and broader understanding of the implementation of design methods and processes as contributions to strategic renewal of small and medium-sized enterprises. The research identifies three specific design principles or "imperatives" derived from the data to guide a design team in implementing design-led innovation within a METS company:

1. Design-led change within an engineering-focussed organization should encourage the company leadership to engage with, reflect upon, and disseminate their personal journey with design-led innovation.

2. Company management and employees should experience design-led change first-hand to positively influence company engagement and commitment and project traction in the organizational culture.

3. Internal design-thinking capability should allow METS companies to sustainably generate insights through their limited but valuable customer engagement.

The significance of these findings is shown in the combined implementation of the design imperatives leading towards design-led change at all business levels of an organizational structure. These imperatives are illustrated in Figure 3.

This research highlighted three levels of organizational change at the leadership, management, and employee levels that occurred as a result of the 11-month embedded design-led innovation engagement with the researcher acting as a catalyst for change within this Australian METS company. Changes observed throughout the organization include the company vision, leadership, innovation, problem solving, customer centricity - all of these aspects demonstrated a shift from an engineering culture to a new more inclusive, customer-centric way of thinking and operating. The design-led change model brings together three elements: i) the level in the organization in which designled change was being applied, ii) each design imperative that emerged from each paradigm of business, and iii) the change that emerged as a result, as shown in Figure 4.

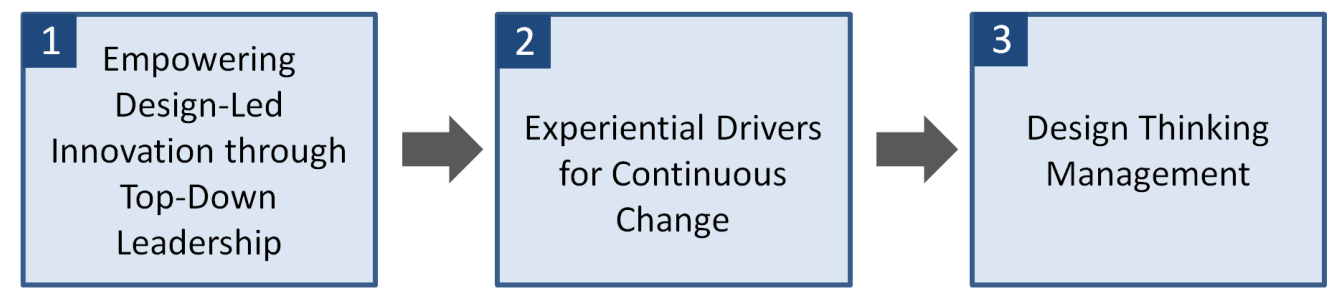

Figure 3. Three design imperatives (principles) for a design-led innovation engagement within the mining equipment, technology, and services industry 


\section{Applying Design-Led Innovation in an Australian Manufacturing Firm}

Peter Townson, Judy Matthews, and Cara Wrigley

Business Levels

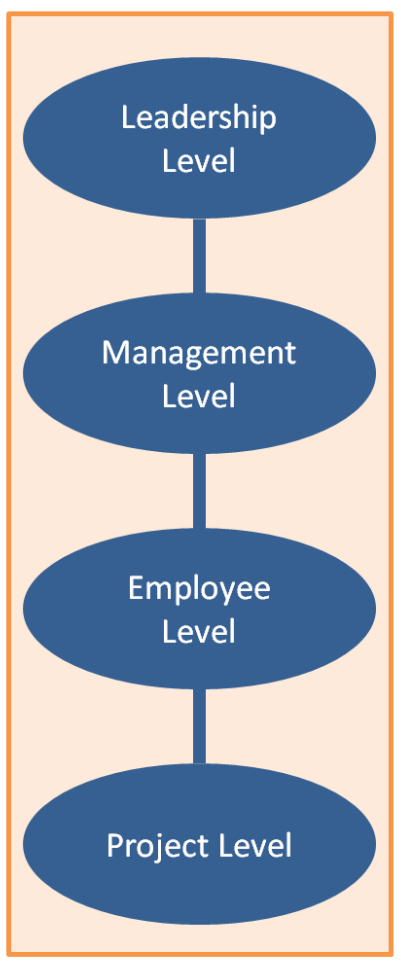

Design Imperatives

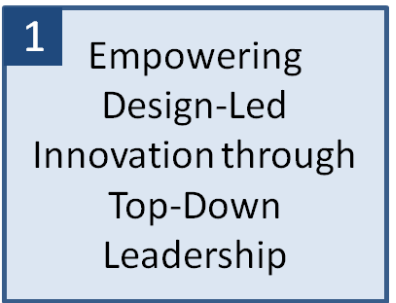

2

Experiential Drivers

for Continuous

Change

3

Design Thinking

Management

\section{.}
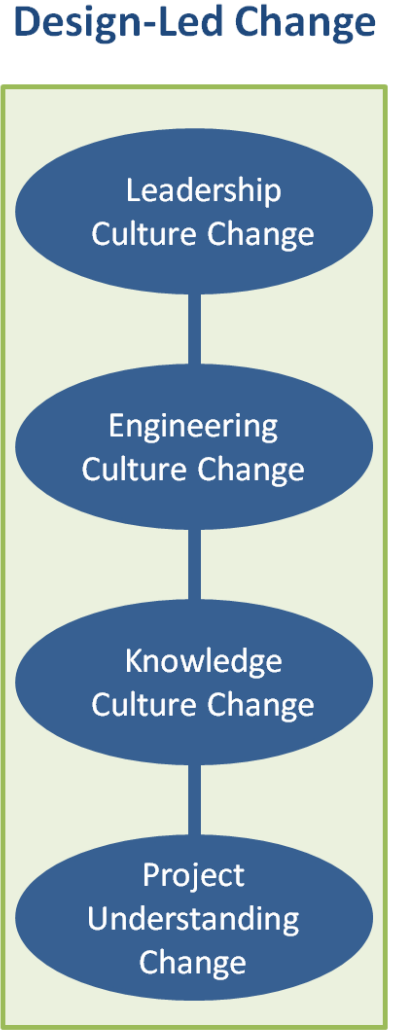

Figure 4. The design-led change model

For METSCo, a deeper understanding of their customers was a large part of the value offering of the catalyst. The researcher was perceived to be creating value in relation to the firm, the industry, and academia. For example, the company linked the introduction of a design-led approach to developing a new customer-focused business model and to the shift of the organizational culture from an engineering culture to a more customer-focused innovation culture. The researcher's role was respectively described by employees as a change catalyst, a knowledge disseminator, and an organizational culture reformist.

\section{Conclusions}

This research contributes new knowledge regarding the possibilities that design-led innovation brings to organizations seeking to continuously innovate in dynamic markets. It also highlights the important role of designers as innovation catalysts in building strong links to existing and potential customers. Working with the company and engaging and educating organizational members with design tools and approaches through direct experience has taken the company some distance on the journey with design-led innovation. The practical application of various methods of the designled innovation framework had a positive impact on the firm's interactions with customers and generated new business opportunities with these customers. Action research's unique and collaborative approach to working with the participating company also contributes to the research aim of using design-led innovation as a mechanism to bring about organizational change.

The research identifies three specific design principles or "imperatives" that guide a design team in implementing design-led innovation within a company. This study explores the processes of introduction, implementation, and integration of design-led innovation within a manufacturing company driven by engineering innovation in a sector dominated by product and process improvements.

Companies engaged in a design-led program have to develop strategies for capturing the value from new knowledge generated through customer insights. Practical implications for the firm as a whole include the benefits of bringing new ways of thinking and working into technologically focused company with a tightly defined engineering culture. 


\section{Applying Design-Led Innovation in an Australian Manufacturing Firm}

Peter Townson, Judy Matthews, and Cara Wrigley

Implications for designers engaged in design-led innovation within exisiting firms seeking to change their understanding include the importance of designers with a deep understanding of innovation acting as innovation catalysts. As an active and trusted member of the company, the designer led the capture of insights from multiple customers, became a translator of information from customer insights, and also contributed to organizational change. The designer as innovation catalyst gathered and generated meaning from the customer insights, developed employee capability with the customer-facing employees (who were the main direct contact with the customers on mine sites), and shaped new initiatives for the business and facilitated the translation of customer insights into meaningful business opportunities. This study adds further support to the value of experienced designers acting as innovation catalysts to facilitate organizational transformation through designled innovation.

\section{Acknowledgements}

An earlier version of this article was presented at the 2015 ISPIM Innovation Summit in Brisbane, Australia, December 6-9, 2015. ISPIM (ispim.org) - the International Society for Professional Innovation Management - is a network of researchers, industrialists, consultants, and public bodies who share an interest in innovation management.

\section{About the Authors}

Peter Townson is a Design Facilitator for the PwC Chair in Digital Economy at the Queensland University of Technology (QUT) in Brisbane, Australia, where he recently completed his Master's degree in design-led innovation. Peter lives the world of design in the nexus between academia and industry. From his background as an industrial designer and manufacturer, his translation of his craft from the physical world and into the service and digital worlds' builds off his post-graduate education and application of design-led innovation. Peter now facilitates innovation sprints that use design-led innovation to envision and design the future of our digital economy, while making his findings relevant to the applied academic audience of today.
Judy Matthews is a Senior Lecturer at the Queensland University of Technology (QUT) Business School in Brisbane, Australia, where she teaches both MBAs and senior executives on the topics of innovation management, facilitates problem framing and problem solving in complex environments, and uses design thinking to develop and execute new possibilities. Her enthusiasm for the importance of innovation management can be traced to her research into innovation systems in Australia, in public sector research, and development and in the management of change. For the last six years, Judy has been an active researcher and facilitator in the development and application of design mindsets and methods, recognizing that the frameworks, tools, and mindsets of designers can be used to help managers to problem solve and innovate in their businesses and develop new business models. Judy holds a $\mathrm{PhD}$ from QUT and has published articles in a wide range of international journals, including the Journal of Business Research, the International Journal of Technology Management, Innovation: Management, Policy and Practice, and the Design Management Journal.

Cara Wrigley is Head of Research in the Design \& Innovation Research Centre at the University of Technology Sydney (UTS), Australia. The Design \& Innovation Research Centre (DI:rc) is a transdisciplinary centre located at UTS, focusing on the development of innovative, design-oriented research with the potential to transform companies. Building on her solid practical industry experience and combined with her scholarly expertise in emotional design, she is actively researching the value that design holds in business - specifically through the creation of strategies to design business models which lead to emotive customer engagement. Cara has presented and published widely in the field of design-led innovation and currently leading several initiatives to contribute to both industry and academia on the value of design to business. She holds a $\mathrm{PhD}$ and a Bachelor of the Built Environment from the Queensland University of Technology (QUT) in Brisbane, Australia, in addition to a Bachelor of Design Studies from Griffith University in South East Queensland, Australia. 


\section{Applying Design-Led Innovation in an Australian Manufacturing Firm}

Peter Townson, Judy Matthews, and Cara Wrigley

\section{References}

Austmine. 2013. Australia's New Driver For Growth: Mining Equipment Technology and Services. Sydney: Austmine.

Beckman, S., \& Barry, M., 2009. Design and Innovation through Storytelling. International Journal of Innovation Science, 1(4): 155-160. http://dx.doi.org/10.1260/1757-2223.1.4.151

Beckman, S., \& Barry, M., 2007. Innovation as a Learning Process: Embedding Design Thinking. California Management Review, 50(1): 25-56.

http://dx.doi.org/10.2307/41166415

Brown, T. 2008. Design Thinking. Harvard Business Review, 86(6): 85-92.

Brown, T., \& Martin, R. 2015. Design for Action: How to Use Design Thinking to Make Great Things Actually Happen. Harvard Business Review, 93(9): 57-74.

Bucolo, S., Wrigley, C., \& Matthews, J. 2012. Gaps in Organisational Leadership: Linking Strategic and Operational Activities through Design-Led Propositions. Design Management Journal, 7(1): 18-28. http://dx.doi.org/10.1111/j.1948-7177.2012.00030.x

Bucolo, S., \& Matthews, J. 2011a. A Conceptual Model to Link Deep Customer Insights to Both Growth Opportunities and Organisational Strategy in SME's as Part of a Design Led Transformation Journey. Paper presented at Design Management: Towards a New Era of Innovation, DMI International Design Management Symposium, December 3-5, 2011, Hong Kong. http://eprints.qut.edu.au/47895/

Bucolo, S., \& Matthews, J. 2011b. Design Led Innovation - Exploring the Synthesis of Needs, Technologies and Business Models. In Proceedings of the Participatory Interaction Conference, January 13-15, 2011, Sønderborg, Denmark.

Burns, J., \& Brown, N. 2002. Integrate: A Critical Look at the Interface between Business and Design. Wellington, New Zealand: New Zealand Trade and Enterprise Design Industry Taskforce.

Casadesus-Masanell, R., \& Ricart, J. E. 2010. From Strategy to Business Models and onto Tactics. Long Range Planning, 43(2-3): 195-215.

http://dx.doi.org/10.1016/j.lrp.2010.01.004

Chesbrough, H., \& Schwartz, K. 2007. Innovating Business Models with Co-Development Partnerships. Research-Technology Management, 50(1): 55-59.

http://dx.doi.org/10.1080/08956308.2007.11657419

Chang, Y., Kim, J., \& Joo, J. 2013. An Exploratory Study on the Evolution of Design Thinking: Comparison of Apple and Samsung. Design Management Journal, 8(1): 22-34. http://dx.doi.org/10.1111/dmj.12001

Chhatpar, R. 2007. Innovate Faster by Melding Design and Strategy. Harvard Business Review, 85(9): 2007-2009.

Cohen, E., \& Tichy, N. 1997. How Leaders Develop Leaders. Training and Development, 51(5): 58.

Cross, N. 1982. Designerly Ways of Knowing. Design Studies, 3(4): 221-227.

http://dx.doi.org/10.1162/074793601750357196

CSIRO. 2003. On The Front Line. Earthmatters: CSIRO Exploration and Mining Quarterly Magazine, (2): 20.
Davis, J. 2004. Writing an Action Research Thesis: One Researcher's Resolution of the Problematic of Form and Process. In E. McWilliam, S. Danby, \& J. Knight (Eds.), Performing Educational Research: Theories, Methods and Practices: 15-30. Eumundi, Australia: Post Pressed.

Hall, A., Melin, L., \& Nordqvist, M. 2001. Entrepreneurship as Radical Change in the Family Business: Exploring the Role of Cultural Patterns. Family Business Review, 14(3): 193-208. http://dx.doi.org/10.1111/j.1741-6248.2001.00193.x

Hollinger, T.D. 2012. Better by Design: Using Organizational Design for Competitive Advantage in the 21st Century. Regent Global Business Review, 5(2): 16-22.

Kemmis, S. 2009. Action Research as a Practice-Based Practice. Educational Action Research, 17(3): 463-474. http://dx.doi.org/10.1080/09650790903093284

Kolko, J. 2015. Design Thinking Comes of Age. Harvard Business Review, 93(9): 66-71.

Kolb, D. A. 1984. Experiential Learning: Experience as the Source of Learning and Development. Englewood Cliffs, NJ: Prentice-Hall.

Kyffin, S., \& Gardien, P. 2009. Navigating the Innovation Matrix: An Approach to Design-led Innovation. International Journal of Design, 3(1): 57-69.

Liedtka, J. 2015. Perspective: Linking Design Thinking with Innovation Outcomes through Cognitive Bias Reduction. Journal of Product Innovation Management, 32(6): 925-938. http://dx.doi.org/10.1111/jpim.12163

Martin, R. L. 2011. The Innovation Catalysts, Harvard Business Review, 89(6): 82-87.

Martin, R. 2007. Design and Business: Why Can't We Be Friends? Journal of Business Strategy, 28(4): 6-12. http://dx.doi.org/10.1108/02756660710760890

Martin, R. 2004. The Design of Business. Rotman Management, Winter 2004: 7-12.

Martin, R. 2009. The Design of Business: Why Design Thinking is the Next Competitive Advantage. Boston, MA: Harvard Business School Publishing.

Martinez-Fernandez, C. 2010. Knowledge-Intensive Service Activities in the Success of the Australian Mining Industry. The Service Industries Journal, 30(1): 55-70. http://dx.doi.org//10.1080/02642060802317820

Matthews, J., \& Bucolo, S. 2011. Continuous Innovation in SMEs: How Design Innovation Shapes Business Performance through Doing More with Less. In Proceedings of the 12th International CINet Conference: Continuous Innovation: Doing More with Less: 696-708. Aarhus, Denmark: CINet.

Matthews, J., Bucolo, S., \& Wrigley, C. 2012. Challanges and Opportunities in the Journey of the Design-Led Innovation Champions. In E. Bohemia, J. Liedtka, \& A. Rieple (Eds.), Leading Innovation Through Design: Proceedings of the DMI 2012 International Research Conference: 768-775. Boston, MA: DMI.

McGrath, R. G. 2010. Business Models: A Discovery Driven Approach. Long Range Planning, 43(2-3): 247-261. http://dx.doi.org/10.1016/j.lrp.2009.07.005

Miles, M. B., \& Huberman, M. A. 1994. Qualitative Data Analysis: An Expanded Sourcebook (2nd ed.). Thousand Oaks, CA: SAGE Publications Inc. 


\section{Applying Design-Led Innovation in an Australian Manufacturing Firm \\ Peter Townson, Judy Matthews, and Cara Wrigley}

O'Regan, N., Ghobadian, A., \& Sims, M. 2006. Fast Tracking Innovation in Manufacturing SMEs. Technovation, 26(2): 251-261. http://dx.doi.org/10.1016/j.technovation.2005.01.003

Pascale, T., \& Sternin, J. 2005. Your Company's Secret Change Agents. Harvard Business Review, 83(5): 1-10.

Pozzey, E., Wrigley, C., \& Bucolo, S. 2012. Unpacking the Opportunities for Change within a Family Owned Manufacturing SME: A Design Led Innovation Case Study. In E. Bohemia, J. Liedtka, \& A. Rieple (Eds.), Leading Innovation Through Design: Proceedings of the DMI 2012 Internationa Research Conference: 841-855. Boston, MA: DMI.

Schein, E. H. 1996. Culture: The Missing Concept in Organization Studies. Administrative Science Quarterly, 41(2): 229-240. http://www.jstor.org/stable/2393715

Schön, D. A. 1983. The Reflective Practitioner: How Professionals Think in Action. New York: Basic Books.

Smith, B. 2015. How I Did It: Intuit's CEO on Building a DesignDriven Company. Harvard Business Review, 93(1-2): 35-38.

Swann, C. 2002. Action Research and the Practice of Design. Design Issues, 18(1): 49-61.

http://dx.doi.org/10.1162/07479360252756287

Tedesco, L., \& Curtotti, R. 2005. Mining Technology Services: A Review of the Sector in Australia. Canberra: Australian Bureau of Agriculture and Resource Economics.
Teece, D. J. 2010. Business Models, Business Strategy and Innovation. Long Range Planning, 43(2-3): 172-194. http://dx.doi.org/10.1016/j.lrp.2009.07.003

Verganti, R. 2009. Design Driven Innovation: Changing the Rules of Competition by Radically Innovating What Things Mean. Boston, MA: Harvard Business Press.

Ward, A., Runcie, E., \& Morris, L. 2009. Embedding Innovation: Design Thinking for Small Enterprises. Journal of Business Strategy, 30 (2/3): 78-84. http://dx.doi.org/10.1108/02756660910942490

Wrigley, C., \& Bucolo, S. 2012. New Organisational Leadership Capabilities: Transitional Engineer the New Designer? In Leading Innovation Through Design: Proceedings of the DMI 2012 International Research Conference: 913-922. Boston, MA: DMI. http://eprints.qut.edu.au/53947/

Yoo, Y., \& Kim, K. 2015. How Samsung Became a Design Powerhouse. Harvard Business Review, 93(9): 73-78.

Zott, C., \& Amit, R. 2010. Business Model Design: An Activity System Perspective. Long Range Planning, 43(2-3): 216-226. http://dx.doi.org/10.1016/j.lrp.2009.07.004

Citation: Townson, P., Matthews, J., \& Wrigley, C. 2016. Outcomes from Applying Design-Led Innovation in an Australian Manufacturing Firm. Technology Innovation Management Review, 6(6): 49-58. http://timreview.ca/article/997

Keywords: manufacturing, design-led innovation, innovation catalyst, manufacturing, customer insights 